Tropical Journal of Pharmaceutical Research May 2020; 19 (5): 1093-1098

ISSN: $1596-5996$ (print); 1596-9827 (electronic)

(C) Pharmacotherapy Group, Faculty of Pharmacy, University of Benin, Benin City, 300001 Nigeria.

Available online at http://www.tjpr.org

Original Research Article

http://dx.doi.org/10.4314/tjpr.v19i5.27

\title{
Effect of different doses of dexmedetomidine on lung function and tissue cell apoptosis in a rat model of hyperoxic acute lung injury
}

\author{
Yan Yang ${ }^{1}$, Xian Qin ${ }^{1}$, Chuangang Han ${ }^{1}$, Yan Huang ${ }^{1}$, Lei Jin ${ }^{1}$, Qingqing Liuㄹ, \\ Quan $\mathrm{Hu}^{2 *}$ \\ ${ }^{1}$ Department of Anesthesiology, ${ }^{2}$ Intensive Care Unit, The First People's Hospital of Jiangxia District, Wuhan, PR China
}

*For correspondence: Email: u40pct@163.com

Sent for review: 5 March 2020

Revised accepted: 27 April 2020

\begin{abstract}
Purpose: To study the effect of different doses of dexmedetomidine on lung function and lung tissue cell apoptosis in a rat model of hyperoxic acute lung injury.

Methods: Five groups of healthy male Sprague-Dawley rats were used: normal rats, untreated hyperoxic rats, and hyperoxic rats given 3 different doses of dexmedetomidine, with 20 rats in each group. The levels of interleukin-6 (IL-6) and tumor necrosis factor- $\alpha$ (TNF- $\alpha$ ) were determined using enzyme-linked immunosorbent assay (ELISA). Parietal paraffin cuts were taken from the right upper lobe for measurement of apoptosis using in situ terminal deoxynucleotidyl transferase dUTP nick end labeling (TUNEL), and the apoptosis index was calculated.

Results: At 24 and 48 h, the levels of IL-6 and TNF- $\alpha$ in the hyperoxia model group were significantly higher than those in the normal control group, and their levels in the middle- and high-dose groups were markedly lowered, relative to untreated hyperoxia rats $(p<0.05)$. Apoptosis index in the hyperoxia model rats significantly increased, relative to normal rats $(p<0.05)$. The apoptosis index in the mediumand high-dose groups decreased significantly $(p<0.05)$.

Conclusion: Dexmedetomidine inhibits inflammatory responses caused by high concentration of oxygen inhalation, minimizes lung injury, improves lung function and inhibits lung apoptosis.
\end{abstract}

Keywords: Dexmedetomidine, Hyperoxia, Acute lung injury, Lung function, Apoptosis

\begin{abstract}
This is an Open Access article that uses a fund-ing model which does not charge readers or their institutions for access and distributed under the terms of the Creative Commons Attribution License (http://creativecommons.org/licenses/by/4.0) and the Budapest Open Access Initiative (http://www.budapestopenaccessinitiative.org/read), which permit unrestricted use, distribution, and reproduction in any medium, provided the original work is properly credited.
\end{abstract}

Tropical Journal of Pharmaceutical Research is indexed by Science Citation Index (SciSearch), Scopus, International Pharmaceutical Abstract, Chemical Abstracts, Embase, Index Copernicus, EBSCO, African Index Medicus, JournalSeek, Journal Citation Reports/Science Edition, Directory of Open Access Journals (DOAJ), African Journal Online, Bioline International, Open-J-Gate and Pharmacy Abstracts

\section{INTRODUCTION}

Inhalation of high concentration of oxygen is one of the most common and necessary treatments in clinical rescue, and it plays an important role in maintaining stable organ function, preventing organ failure, gaining time for clinical treatment, and saving patients' lives [1]. However, it has been found that long-term inhalation of high oxygen concentration causes significant adverse reactions to organs, with the lungs as the most prone to hyperoxia-type acute injury. In severe cases, acute respiratory distress syndrome may develop, which seriously threatens the health and quality of life of patients [2]. 
Studies have shown that acute lung injury is closely related to oxidative stress, inflammatory response and apoptosis [3]. Hyperoxia may lead to accumulation of large amounts of ROS and promote the expressions of various inflammatory factors in the lungs. Dexmedetomidine is a highly selective $\alpha 2$ adrenergic receptor agonist that reduces catecholamine levels and inhibits apoptosis [4]. Research has shown that dexmedetomidine protects the lungs by controlling inflammatory response, reducing oxidative stress, and improving lung oxygenation. However, there are limited reports on its application in hyperoxic acute lung injury [5].

This study was carried out to investigate the effect of dexmedetomidine on lung function and apoptosis in a rat model of hyperoxic acute lung injury.

\section{EXPERIMENTAL}

\section{Animals}

A total of 100 healthy male SD rats provided by Guangdong Medical Experimental Animal Center, production license SCXK (Guangdong) 2018-0035), were used. The rats had a mean weight of $223 \pm 37 \mathrm{~g}$. All rats were adaptively reared for 1 week at a temperature of $25 \pm 2{ }^{\circ} \mathrm{C}$, humidity of $52 \pm 5 \%$ and 12-h day/12-h night photoperiod.

This research was approved by the Animal Ethical Committee of Intensive Care Unit, The First People's Hospital of Jiangxia District, Wuhan, PR China (approval no. 201834004), and performed according to "Principles of Laboratory Animal Care" (NIH publication no. 8523, revised 1985) [6].

\section{Main instruments and reagents}

The instruments and reagents used, and their suppliers (in brackets) were: oxygen box (Guangzhou Huayuehang Instrument Co. Ltd., model: H135); ultra-low temperature refrigerator (Shanghai Tianfeng Industrial Co. Ltd., model: TF-86-200-WA); electronic biological microscope (Shenzhen Chensheng Optical Instrument Co. Ltd., Model: SC-Y409A); cryogenic high speed centrifuge (Beijing Times Beili Centrifuge Co. Ltd., Model: GT16-3); arterial blood gas analyzer (Nanjing Baden Medical Co. Ltd., Model: BC5000); dexmedetomidine (Jiangsu Hengrui Pharmaceutical Co. Ltd., production batch number: 20170248, specification: 2ml: 200g); TNF- $\alpha$ detection kit (Shanghai Jimian Industrial Co. Ltd., specification: 96T); IL-6 detection kit
(Beijing Rejing Biotechnology Co., Ltd., Specification: 40T).

\section{Grouping and establishment of animal model}

The 100 SD rats were randomly divided into normal control, hyperoxic model, low-dose dexmedetomidine (low-dose), medium-dose dexmedetomidine (medium-dose), and high-dose dexmedetomidine (high-dose) groups. Each group had 20 rats. The normal control group rats were fed normally without treatment. Rats in the hyperoxic model group were reared in a hyperoxic environment for more than 23 hours but less than 24 hours per day. The rats were given dexmedetomidine at a dose of 30 (low dose), 60 (medium dose) or $90 \mu \mathrm{g} / \mathrm{kg}$ (high dose).

\section{Treatment indicators}

The rats were anesthetized at 24 and $48 \mathrm{~h}$ after the test, and $0.6 \mathrm{ml}$ of arterial blood was taken from each rat. Oxygenation index and respiratory index were measured using an arterial blood gas analyzer and computed as in Eqs 1 and 2.

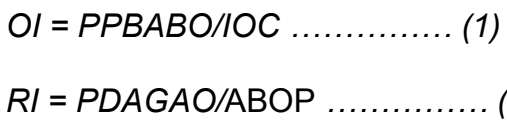

where $\mathrm{OI}$ is oxygenation index, PPABO is partial pressure of arterial blood oxygen, IOC is inhaled oxygen concentration, $\mathrm{RI}$ is respiratory index, PDAGAO is pressure difference in alveolar gas arterial oxygen and $\mathrm{ABOP}$ is arterial blood oxygen pressure.

The levels of interleukin-6 (IL-6) and tumor necrosis factor- $\alpha$ (TNF- $\alpha$ ) in each group were determined with ELISA. The lungs of each group of rats were separated, the upper lobes of the left lungs were subjected to H\&E staining for determination of pathological changes. Paraffin sections of the right upper lobes were subjected to apoptosis determination using TUNEL assay, and the apoptosis index was calculated.

\section{Statistical analysis}

All statistical analyses were done with SPSS 18.0 software package. Measurement data were subjected to multi-group comparison using single factor multi-sample method, while two-groups were compared with independent sample $t$-test. Count data comparison was performed with $X^{2}$ test. Grade data comparison was performed using Ridit test. Values of $p<0.05$ were taken as indicative of statistical significance of difference. 


\section{RESULTS}

\section{Changes in oxygenation index and respiratory index amongst the groups}

As presented in Table 1, oxygenation index and respiratory index of hyperoxic model rats were markedly reduced at 24 and $48 \mathrm{~h}$, relative to control $(p<0.05)$. Compared with the hyperoxia model group, these indices were significantly increased in the middle-dose and high-dose groups $(p<0.05)$.

\section{Levels of IL- 6 and TNF- $\alpha$}

Table 2 shows that after 24 and $48 \mathrm{~h}$, the levels of IL-6 and TNF- $\alpha$ were markedly elevated in hyperoxic model rats, relative to their corresponding values in normal control rats, but were markedly higher than those in middle-dose and high-dose rats $(p<0.05)$.

\section{Lung pathology}

The alveolar structure of rats in the normal control group was clear without congestion and inflammatory cell infiltration. In the hyperoxic model group, the lung tissue was disordered, the number of alveoli was reduced, and inflammatory cell infiltration was obvious, with presence of edema. Lung tissue in low-dose group was similar to that in the hyperoxia model group, but with slight improvement. Lung injury in middleand high-dose rats showed marked improvement, relative to hyperoxic model rats, but the middle-dose rats showed more obvious improvement. These results are shown in Figure 1.

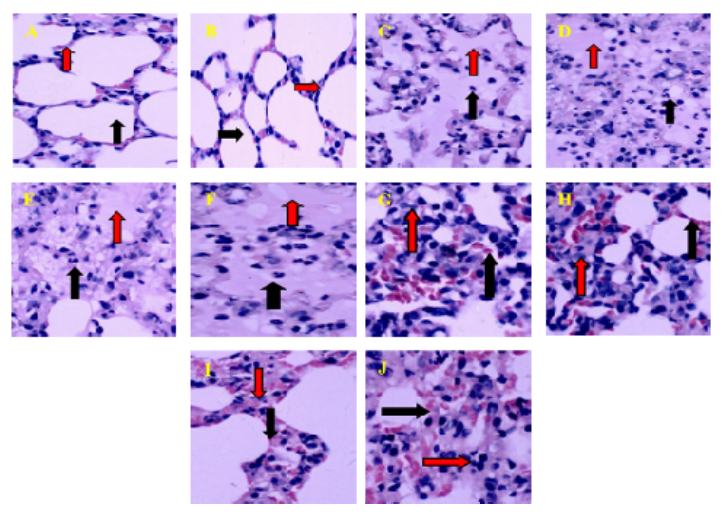

Figure 1: Pathological changes in lung tissue of rats. A: normal control rats after $24 \mathrm{~h}$; $\mathrm{B}$ : normal control rats after $48 \mathrm{~h}$; C: hyperoxia model rats after $24 \mathrm{~h}$; D; hyperoxia model rats after $48 \mathrm{~h}$; $\mathrm{E}$ : low-dose rats after $24 \mathrm{~h}$; F: low-dose rats after $48 \mathrm{~h}$; G: middle-dose rats after $24 \mathrm{~h}$; $\mathrm{H}$ : middle-dose rats after $48 \mathrm{~h}$; I: high-dose rats after $24 \mathrm{~h}$; J: high-dose rats after $48 \mathrm{~h}$

\section{Apoptosis in rat lung tissues}

There was marked increase in apoptotic index in hyperoxia model rats, relative to control rats $(p<$ 0.05). Although there was a reduction in apoptotic index of hyperoxia model rats, it was comparable with that of low-dose rats $(p>0.05)$.

Table 1: Changes in oxygenation index and respiratory index of rats $(n=20)$

\begin{tabular}{lcccc}
\hline \multirow{2}{*}{ Group } & \multicolumn{2}{c}{ Oxygenation index } & \multicolumn{2}{c}{ Respiratory index } \\
\cline { 2 - 5 } & $\mathbf{2 4 h}$ & $\mathbf{4 8 h}$ & $\mathbf{2 4 h}$ & $\mathbf{4 8 h}$ \\
\hline Normal control & $464.51 \pm 15.96$ & $453.15 \pm 13.55$ & $0.07 \pm 0.03$ & $0.08 \pm 0.03$ \\
Hyperoxia model & $301.79 \pm 13.41^{\mathrm{a}}$ & $265.76 \pm 16.27^{\mathrm{a}}$ & $0.41 \pm 0.06^{\mathrm{a}}$ & $0.51 \pm 0.07^{\mathrm{a}}$ \\
Low-dose & $309.18 \pm 11.75^{\mathrm{a}}$ & $271.41 \pm 13.14^{\mathrm{a}}$ & $0.39 \pm 0.05^{\mathrm{a}}$ & $0.48 \pm 0.06^{\mathrm{a}}$ \\
Middle-dose & $379.18 \pm 10.14^{\mathrm{ab}}$ & $327.04 \pm 11.65^{\mathrm{ab}}$ & $0.22 \pm 0.03^{\mathrm{ab}}$ & $0.31 \pm 0.07^{\mathrm{ab}}$ \\
High-dose & $375.68 \pm 11.86^{\mathrm{abc}}$ & $312.76 \pm 11.93^{\mathrm{abc}}$ & $0.21 \pm 0.03^{\mathrm{abc}}$ & $0.32 \pm 0.06^{\mathrm{abc}}$ \\
$F$ & 530.67 & 638.26 & 226.14 & 163.97 \\
$P$-value & $<0.001$ & $<0.001$ & $<0.001$ & $<0.001$ \\
\hline
\end{tabular}

Data are mean \pm SD. ${ }^{a} P<0.05$, vs normal control; ${ }^{b} p<0.05$, vs hyperoxia model rats; ${ }^{c} p<0.05$, vs low-dose rats

Table 2: IL-6 and TNF- $\alpha$ levels amongst the groups $(n=20)$

\begin{tabular}{lcccc}
\hline \multirow{2}{*}{ Group } & \multicolumn{2}{c}{ IL-6 $\mathbf{( p g / m L})$} & \multicolumn{2}{c}{ TNF- $\boldsymbol{\alpha}(\mathbf{p g} / \mathbf{m L})$} \\
\cline { 2 - 5 } & $\mathbf{2 4 h}$ & $\mathbf{4 8 h}$ & $\mathbf{2 4 h}$ & $\mathbf{4 8 h}$ \\
\hline Normal control & $23.31 \pm 2.15$ & $24.26 \pm 1.07$ & $32.06 \pm 2.63$ & $35.73 \pm 1.28$ \\
Hyperoxia model & $32.82 \pm 1.51^{\mathrm{a}}$ & $36.29 \pm 1.08^{\mathrm{a}}$ & $56.81 \pm 1.96^{\mathrm{a}}$ & $63.06 \pm 3.24^{\mathrm{a}}$ \\
Low-dose & $31.46 \pm 3.29^{\mathrm{a}}$ & $35.08 \pm 2.73^{\mathrm{a}}$ & $55.14 \pm 2.96^{\mathrm{a}}$ & $61.44 \pm 3.28^{\mathrm{a}}$ \\
Middle-dose & $25.96 \pm 2.49^{\mathrm{ab}}$ & $27.28 \pm 2.49^{\mathrm{ab}}$ & $45.97 \pm 3.75^{\mathrm{ab}}$ & $49.76 \pm 4.88^{\mathrm{ab}}$ \\
High-dose & $26.65 \pm 1.81^{\mathrm{abc}}$ & $29.35 \pm 2.31^{\mathrm{abc}}$ & $46.47 \pm 2.42^{\mathrm{abc}}$ & $51.21 \pm 4.62^{\mathrm{abc}}$ \\
$F$ & 58.06 & 123.38 & 245.08 & 176.89 \\
$P$-value & $<0.001$ & $<0.001$ & $<0.001$ & $<0.001$ \\
\hline
\end{tabular}

Results are mean \pm SD. ${ }^{a} P<0.05$, vs normal control rats; ${ }^{b} p<0.05$, vs hyperoxia model rats; ${ }^{c} p<0.05$, vs lowdose rats 
Moreover, apoptosis index of lung tissue of rats was reduced markedly in middle- and high-dose rats $(p<0.05)$. These results are shown in Figure 2 and Table 3.
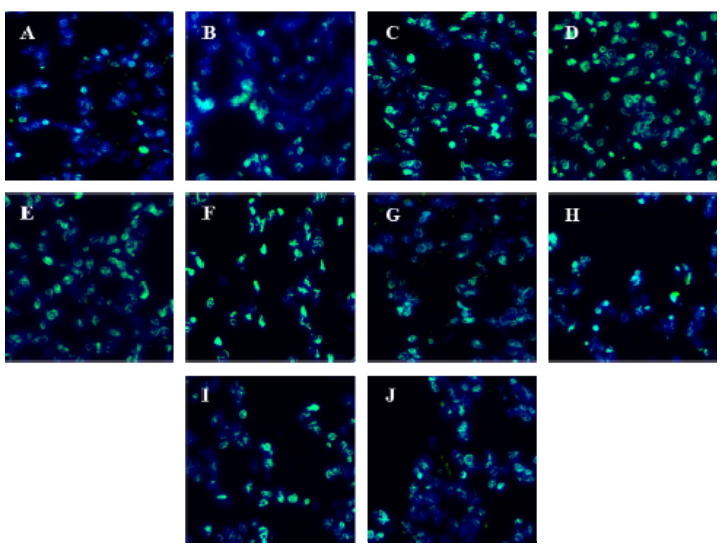

Figure 2: Visual comparison of lung tissue apoptosis amongst the various groups. A: normal control rats after $24 \mathrm{~h}$; B: normal rats after $48 \mathrm{~h}$; C: hyperoxic model rats after $24 \mathrm{~h}$; $\mathrm{D}$; hyperoxia model rats after 48 h; E: low-dose rats after 24 h; F: low-dose rats after 48 h; G: middle-dose rats after $24 \mathrm{~h}$; $\mathrm{H}$ : middle-dose rats after $48 \mathrm{~h}$; I: high-dose rats after $24 \mathrm{~h}$; J: high-dose rats after $48 \mathrm{~h}$

Table 3: Apoptosis index of rat lung tissues $(n=20)$

\begin{tabular}{lcc}
\hline \multirow{2}{*}{ Group } & \multicolumn{2}{c}{ Apoptosis index } \\
\cline { 2 - 3 } & $\mathbf{2 4 h}$ & $\mathbf{4 8 h}$ \\
\hline Normal control & $0.14 \pm 0.02$ & $0.14 \pm 0.02$ \\
Hyperoxic model & $0.38 \pm 0.05^{\mathrm{a}}$ & $0.48 \pm 0.05^{\mathrm{a}}$ \\
Low-dose & $0.35 \pm 0.03^{\mathrm{a}}$ & $0.46 \pm 0.03^{\mathrm{a}}$ \\
Middle-dose & $0.26 \pm 0.06^{\mathrm{ab}}$ & $0.34 \pm 0.07^{\mathrm{ab}}$ \\
High-dose & $0.29 \pm 0.06^{\mathrm{abc}}$ & $0.37 \pm 0.04^{\mathrm{abc}}$ \\
$F$ & 79.36 & 177.86 \\
P-value & $<0.001$ & $<0.001$ \\
\hline
\end{tabular}

Data are mean \pm SD. ${ }^{a} P<0.05$, vs normal rats; ${ }^{b} p<$ 0.05 , vs hyperoxia model rats; ${ }^{c} p<0.05$, vs low-dose rats

\section{DISCUSSION}

Inhalation of high concentrations of oxygen is a common and necessary treatment strategy for patients with severely compromised respiratory system. However, research has shown that high oxygen concentration exerts toxic effects on multiple organs, with the lungs being the most vulnerable [7]. Sprague-Dawley (SD) rats are similar to humans in tissue development, pathophysiology and immune response. Thus, they are now widely used in the study of lung diseases. In this study, SD rats were used to establish a hyperoxia acute lung injury model for studying the effects of different doses of dexmedetomidine on lung function and apoptosis. Dexmedetomidine is a dextro-isomer of a2-body adenosine receptor agonist with a short half-life. It has strong sedative, analgesic and anti-sympathetic effects, and its respiratory inhibition effect alleviates stress response during surgery and reduces the incidence of postoperative complications [8].

In the past, hypoxia was diagnosed only through blood pressure, heartbeat, breathing, and changes in consciousness and skin color. The presence of cyanosis usually means that the arterial blood is highly hypoxic, but this is difficult to detect in patients with dark skin or moderate anemia [9]. Oxygenation index and respiratory index are usually used as indicators of lung function [10]. In this study, the oxygenation index and respiratory index of the hyperoxic model group were markedly reduced at 24 and $48 \mathrm{~h}$, relative to control. Compared with the hyperoxia model group, the oxygenation index and respiratory index of the middle- and high-dose groups were significantly increased. These indices were higher in low-dose group than those in hyperoxia model group, but the two groups were comparable, suggesting that hyperoxia caused severe lung damage which was significantly mitigated by dexmedetomidine.

Studies have found that inflammatory response is one of the important mechanisms involved in hyperoxia lung injury [11]. The release of local or systemic cytokines in the early stage of hyperoxia lung injury destroys the functions of endothelial and epithelial cells. Protein-rich edema fluid accumulates in the alveolar epithelial space, causing infiltration of a large number of inflammatory cells including neutrophils and macrophages, and activation of fibroblasts in the lung, thereby further aggravating lung injury [12]. It is known that IL-6, a lymphokine produced by activated $T$ cells and fibroblasts, induces synthesis of acute phase response proteins [13]. The synthesis and secretion of IL-1 is induced by TNF- $\alpha$, a pro-inflammatory factor, thereby inducing pulmonary vascular endothelial cell injury and pulmonary edema [14]. The results of this study suggest that dexmedetomidine significantly reduces lung tissue inflammation and lung injury, which is consistent with the results of Liu et al [15].

Apoptosis is autonomous and orderly death of cells, a process regulated by genes so as to maintain homeostasis of the internal environment. It is an important histological feature of acute lung injury. The pathogenesis of acute lung injury is closely related to apoptosis. However, moderate apoptosis of cells is beneficial for the removal of inflammatory cells and abnormally proliferating cells from the lung [16]. High concentration of oxygen promotes the 
expression of inflammatory factors e.g. TNF- $\alpha$ in the lung. The TNF- $\alpha$ forms a death-inducing signal complex by binding to its receptor, thereby triggering the caspase cascade and apoptosis [17]. This study has demonstrated that dexmedetomidine inhibited apoptosis of lung tissue cells. It significantly inhibited the inflammatory response caused by inhalation of high concentration of oxygen, reduced lung injury, improved lung function, and inhibited apoptosis of lung tissue cells.

\section{DECLARATIONS}

\section{Conflict of interest}

No conflict of interest is associated with this work.

\section{Contribution of authors}

We declare that this work was done by the author(s) named in this article and all liabilities pertaining to claims relating to the content of this article will be borne by the authors. All authors read and approved the manuscript for publication. Quan $\mathrm{Hu}$ conceived and designed the study, Yan Yang, Xian Qin, Chuangang Han, Yan Huang, Lei Jin, Qingqing Liu, Quan Hu collected and analysed the data, while Yan Yang and Xian Qin wrote the manuscript.

\section{Open Access}

This is an Open Access article that uses a funding model which does not charge readers or their institutions for access and distributed under the terms of the Creative Commons Attribution License (http://creativecommons.org/licenses/by/ 4.0) and the Budapest Open Access Initiative (http://www.budapestopenaccessinitiative.org/rea d), which permit unrestricted use, distribution, and reproduction in any medium, provided the original work is properly credited.

\section{REFERENCES}

1. Yang Z, Lu JT, Li H, Le M, Yan JB, Yuan Y. Influence of dissolved oxygen concentration and exposure temperature on the steam oxidation behaviour of HR3C. Corrosion Eng Sci Technol 2019; 54(10): 1-9.

2. Wen WJ, Lou ZC, Chen YJ, Chen DS, Tian SH, Xiong Y. Tuning the structural properties of $\mathrm{CeO}_{2}$ by $\mathrm{Pr}$ and $\mathrm{Fe}$ codoping for enhanced visible-light catalytic activity. J Chem Technol Biotechnol 2019; 94(5): 1576-1584.

3. Pei JP, Fan LH, Nan K, Li J, Dang XQ, Wang KZ. HSYA alleviates secondary neuronal death through attenuating oxidative stress, inflammatory response, and neural apoptosis in $S D$ rat spinal cord compression injury. $J$ Neuroinflammation 2017; 14: 97.

4. Jun IG, Kwon HM, Jung KW, Moon YJ, Shin WJ, Song JG, Hwang GS. The Impact of Postreperfusion Syndrome on Acute Kidney Injury in Living Donor Liver Transplantation: A Propensity Score Analysis. Anesth Analg 2018; 127(2): 369-378.

5. Fu C, Dai $X$, Yang $Y$, Lin M, Cai $Y$, Cai $S$. Dexmedetomidine attenuates lipopolysaccharideinduced acute lung injury by inhibiting oxidative stress, mitochondrial dysfunction and apoptosis in rats. Mol Med Rep 2017; 15(1): 131-138.

6. World Health Organization. Principles of laboratory animal care. WHO Chron 1985; 39: 51-56.

7. lizuka N, Nakahara T, Ushikubo H, Mori A, Sakamoto K, Ishii K. Retinal region-dependent susceptibility of capillaries to high-concentration oxygen exposure and vascular endothelial growth factor receptor inhibition in neonatal mice. J Pharmacol Sci 2015; 129(2): 107-118.

8. Zhang $Y$, Jia $S$, Gao $T$, Zhang $R$, Liu Z, Wang $Y$. Dexmedetomidine mitigate acute lung injury by inhibiting IL-17-induced inflammatory reaction. Immunobiol 2018; 223(1): 32-37.

9. Smallwood CD, Walsh BK, Arnold JH, Gouldstone A. Equilibration Time Required for Respiratory System Compliance and Oxygenation Response Following Changes in Positive End-Expiratory Pressure in Mechanically Ventilated Children. Crit Care Med 2018; 46(5): 375-379.

10. Dallefeld SH, Spears TG, Zimmerman KO. The Challenges of Identifying an Oxygenation Index Threshold for Increased Mortality in Pediatric Acute Respiratory Failure. Respir Care 2017; 62(10): 1375.

11. Yu S, Shi M, Liu C, Liu Q, Guo J, Yu S, Jiang T. Time course changes of oxidative stress and inflammation in hyperoxia-induced acute lung injury in rats. Iran J Basic Med Sci 2015; 18(1): 98-103.

12. Yao L, Shi $Y$, Zhao $X$, Hou A, Xing $Y, F u ~ J$, Xue $X$. Vitamin $D$ attenuates hyperoxia-induced lung injury through downregulation of Toll-like receptor 4. Int $\mathrm{J} \mathrm{Mol}$ Med 2017; 39(6): 1403-1408.

13. Li H, Wang G, Lin S, Wang C, Zha J. Loss of interleukin6 enhances the inflammatory response associated with hyperoxia-induced lung injury in neonatal mice. Exp Ther Med 2019; 17(4): 3101-3107.

14. Lakshmi G, Ramani S, Mason B, Rajan A, Yeruva RR, Czachor A, Harris F, Lockey RF, Kolliputi N. SOCS-1 rescues IL-1 $\beta$-mediated suppression of epithelial sodium channel in mouse lung epithelial cells via ASK-1. Oncotarget 2016; 7(20): 29081-29091.

15. Liu LP, Li B, Shuai TK, Zhu L, Li YM. Deletion of soluble epoxide hydrolase attenuates mice Hyperoxic acute lung injury. Bmc Anesthesiol 2018; 18(1): 48.

16. Zhang $Y$, Fan $L$, Xi R, Mao Z, Shi D, Ding D, Zhang Z, Wang $X$. Lethal concentration of perfluoroisobutylene induces acute lung injury in mice mediated via cytokine storm, oxidative stress and apoptosis. Inhal Toxicol 2017; 29(6): 255-265.

Trop J Pharm Res, May 2020; 19(5): 1097 
17. Baffour Tonto P, Yasuma T, Kobayashi T, D'AlessandroGabazza CN, Toda M, Saiki H, Fujimoto H, Asayama K, Fujiwara $K$, Nishihama $K$, et al. Protein $S$ is Protective in
Acute Lung Injury by Inhibiting Cell Apoptosis. Int $\mathrm{J} \mathrm{Mol}$ Sci 2019; 20(5): 1082. 